\title{
Effect of Everolimus Adjuvant to Radical Nephrectomy on a Case of Metastatic Papillary Renal Cell Carcinoma
}

\author{
Sossa Jean ${ }^{1 *}$, Fanou Lionelle ${ }^{1}$, Hounto Yao Felicien ${ }^{1}$, Atadokpede Félix ${ }^{1}$, Avakoudjo Dedjinnin Josue Georges ${ }^{2}$
}

\author{
${ }^{1}$ Service d'Urologie, Hôpital d'Instruction des Armées - Centre Hospitalier Universitaire, Camp Guezo, Rue Caporal Ananni, \\ Cotonou, République du Bénin, West Africa \\ ${ }^{2}$ Clinique Universitaire d'Urologie-Andrologie, Centre National Hospitalier Universitaire Hubert Koutoucou Maga, Avenue Jean Paul \\ II, Cotonou, République du Bénin, West Africa
}

DOI: $\underline{10.36347 / \text { sasjs.2021.v07i03.006 }}$

| Received: 26.02.2021 | Accepted: 11.03.2021 | Published: 15.03.2021

*Corresponding author: Sossa Jean

Email: feminawa@yahoo.com

\section{Abstract}

We combined an adjuvant Everolimus therapy and a radical nephrectomy to treat a case of papillary renal cell carcinoma. The latter was revealed by a right limp linked to a pelvic metastasis in a 43 -years-old female. Starting at the fifth post-nephrectomy month, the patient took 10 milligrams of Everolimus daily for 6 months. There was no significant regression of the pelvic (right acetabulum and iliopubic ramus), hepatic (segments IV and V) and spinal metastases (L2 and S1 vertebral bodies). The right acetabulum was fractured which apparently resulted more from the body weight than from a worsening of the metastatic lesion. However no new metastatic sites were noticed. The patient survived for ten months and one week. Everolimus adjuvant to radical nephrectomy had apparently stabilized the metastatic lesions but achieved a less-than-a-year survival in our patient.

Keywords: Everolimus, Nephrectomy, Renal Cell Carcinoma.

Copyright $(\mathcal{C} 2021$ The Author(s): This is an open-access article distributed under the terms of the Creative Commons Attribution 4.0 International License (CC BY-NC 4.0) which permits unrestricted use, distribution, and reproduction in any medium for non-commercial use provided the original author and source are credited.

\section{INTRODUCTION}

Targeted therapies are new breakthroughs in the management of advanced renal cell carcinoma [1]. We intend to evaluate the effect of Everolimus adjuvant to nephrectomy on a case of metastatic papillary renal cell carcinoma.

\section{CASE PRESENTATION}

A 43-years-old female weighing 83 kilograms with a 1.68 meter height (body mass index $=29.41$ kilograms per square meter), complained of a right hip pain coupled with a homolateral limping. The pain had been worsening for nearly two months. On a pelvic $\mathrm{x}-$ ray, there was a thinning with a reduction in bone density of the right superior pubic ramus (Image A). A metastasis was suspected to cause that focal reduction in bone density. An abdominal ultrasonography revealed a mass in the left kidney. On computed tomography, that left renal mass was tissular, poorly vascular and 139.8 millimeters large (Image B). The computed tomography also revealed lombo-aortic lymph nodes, two hepatic metastases (one in segment IV and one in segment V), a partial metastatic lysis of the second lumbar (L2) and first sacral (S1) vertebral bodies (Images C, D, E). The lungs were normal (Image
F). So the patient had cT2N1M1 left kidney tumor. On biological work-up, she presented a calcemia $=93$ milligrams per liter, an hemoglobin level $=9.20$ grams per deciliter, a count of neutrophil white blood cells $=$ $4.34 \times 10^{12}$ per liter and a count of thrombocytes $=3.80$ x $10^{14}$ per liter. Her Karnofsky Performance Status was $70 \%$.

The patient underwent a left radical nephrectomy. On the seventh post-operative day she was discharged from hospital. The histopathological examination of the specimen evidenced a pT3aNOM1 papillary renal cell carcinoma. The surgical margins were negative. The tumor grade was 4 . Sarcomatoid cells were present in the tumor. In sum, the case was that of an intermediary risk disease. We proposed a daily oral $10 \mathrm{mg}$ of Everolimus to the patient from the fifth post-operative week. But the drug was both expensive and unavailable on the local market. Therefore, the adjuvant Everolimus therapy only started at the hundred and twenty-third post-operative day. At that time, the limping had worsened, the patient experienced some difficulty to get up but could stand. In fact, an important lytic lesion partially dissolved the right iliopubic ramus and both the anterior and posterieur walls of the right acetabulum. The right 
medial acetabular wall was fractured. The superior wall of the right acetabulum was preserved, which explained that the patient could stand somewhat easily despite the difficulty to get from the sitting position to the standing one. Later on, the patient fell down during a morning bath and had her already metastasis-fragilized right hip further fractured. She could no longer get up by herself. Three weeks later, i.e ten months and one week after the nephrectomy, she died.

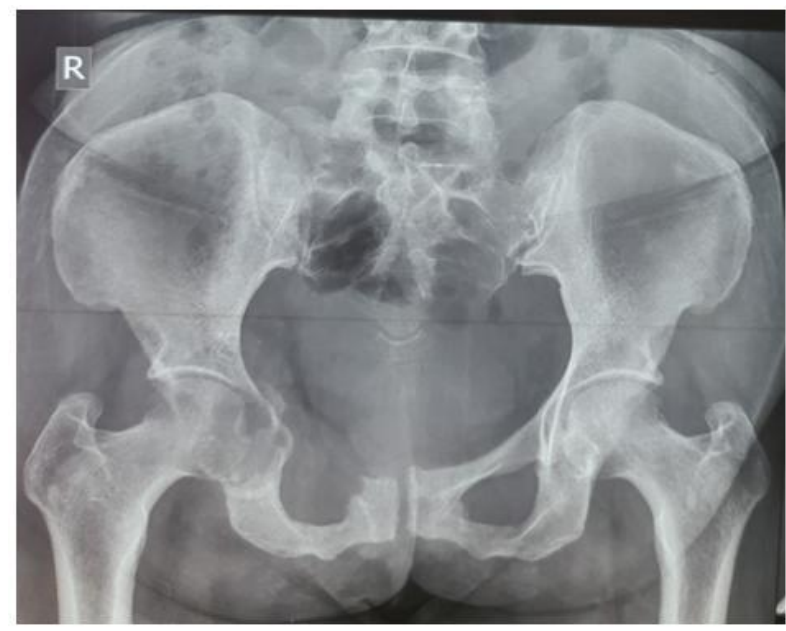

Image-A: Drastic bone density reduction in the right superior pubic ramus on a pelvic $\mathrm{X}$-Ray

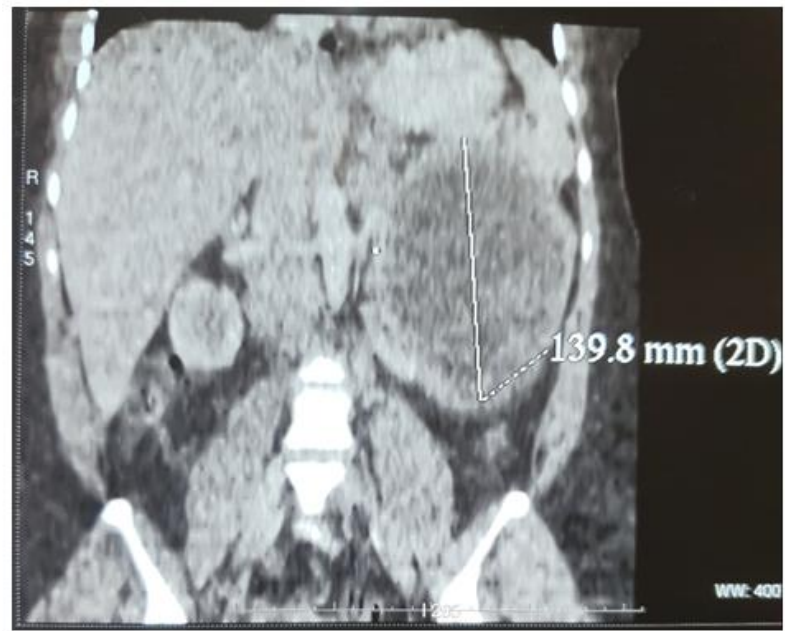

Image-B: Computed tomography showing a left renal mass

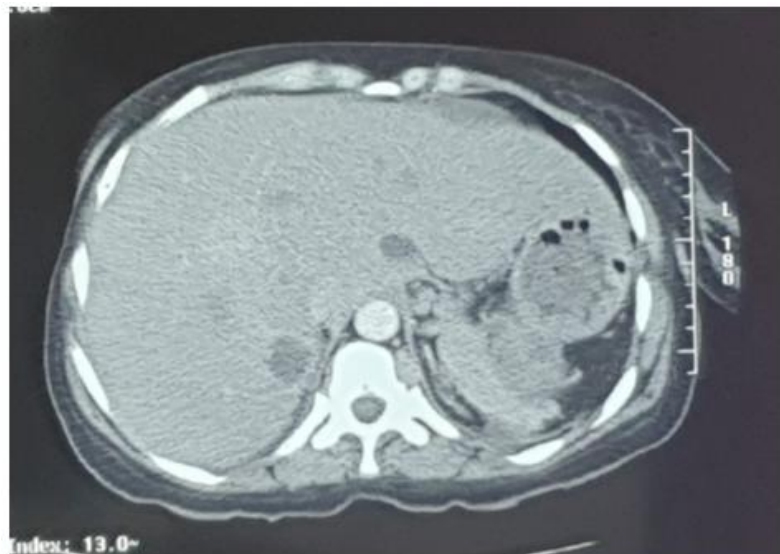

Image-C: Hepatic metastases

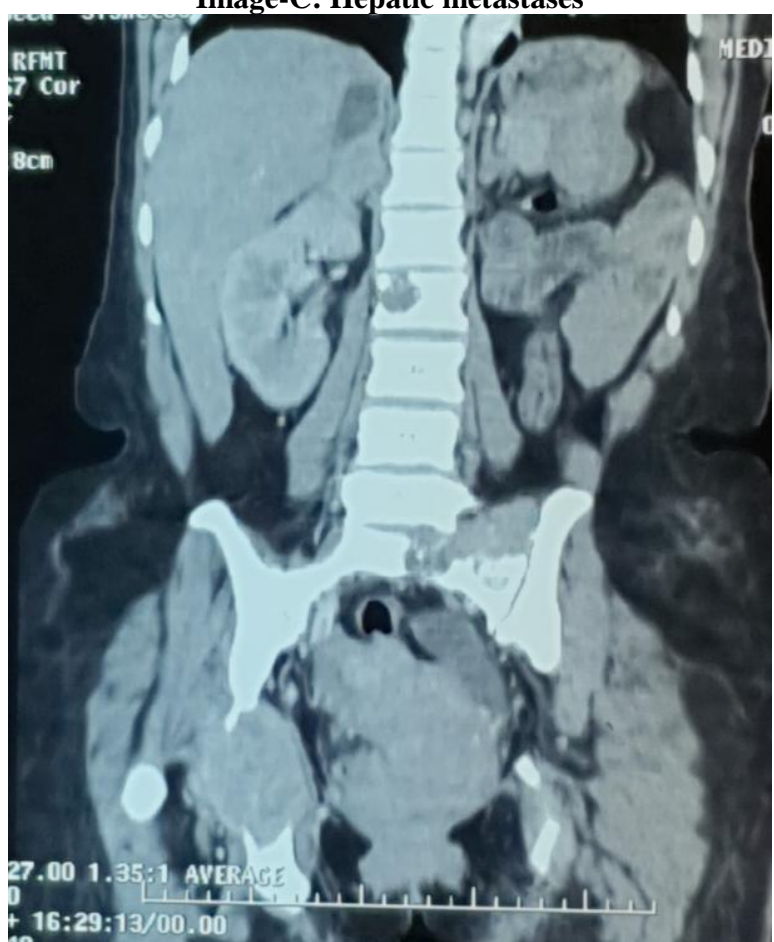

Image-D: Computed tomography showing metastatic lytic lesions in the $2^{\text {nd }}$ second lumbar vertebrae, the $1^{1 \text { st }}$ sacral vertebrae and the right acetabulum

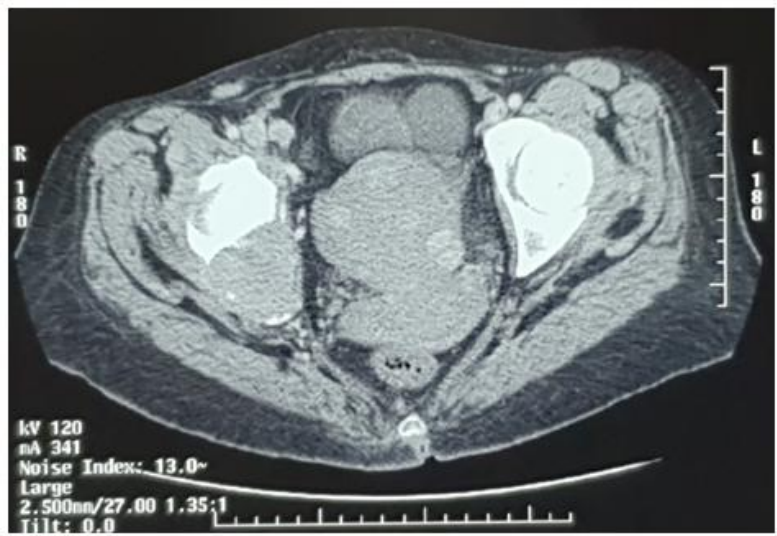

Image-E: Computed Tomography showing a metastatic lysis of the right acetabulum 


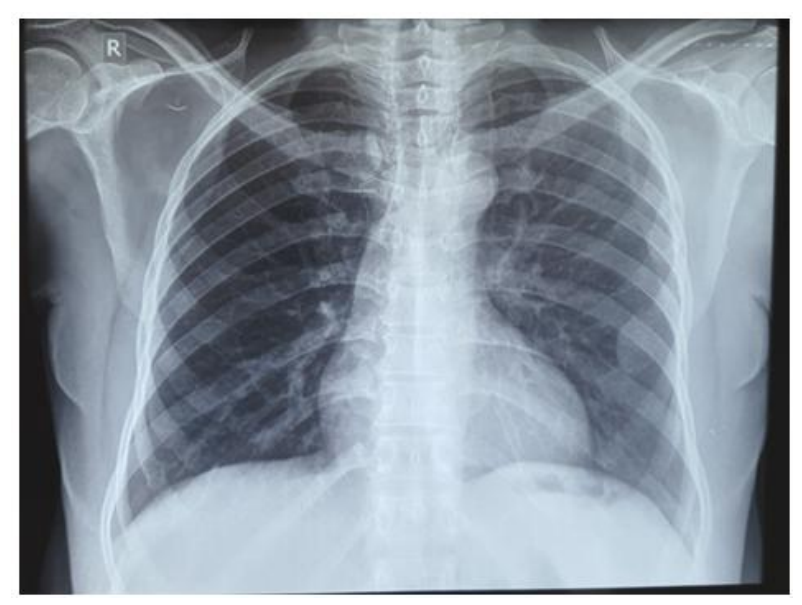

Image-F: No pulmonary metastasis on Chest X-Ray

\section{DISCUSSION}

Treating a metastatic renal cell carcinoma is still a challenge. Although Tyrosine Kinase Inhibitors (TKI) and mammalian Target Of Rapamycin (mTOR) Inhibitors offer a better perspective for metastatic clear cell renal cell carcinoma (ccRCC), their effect seem less clear on metastatic non-ccRCC $[1,2]$. Our patient had a resectable papillary RCC with multiple site metastases. Combining adjuvant Everolimus to radical nephrectomy helped her to survive 10 months. The Everolimus onset was delayed up to the fifth post-operative month, but it was steadily continued until the patient died, i.e for six months. Nevertheless no significant disease regression was achieved. The lytic lesions in the second lumbar and first sacral vertebra seemed stabilized. The hepatic metastatic lesions did not change. No new metastases appeared. A spontaneous acetabular fracture supervened which was furthered as the patient fell while taking a bath. True that the metastasis had fragilized the right acetabulum but the body weight evidently contributed to the spontaneous acetabular fracture. All along the Everolimus therapy, the patient was continuously dependent on analgesics especially for the right hip pain but no longer complained of spinal pain. So, we could hardly appreciate the effect of Everolimus on the metastases-related pain. Some studies have found that Temsirolimus, another mTOR inhibitor, is beneficial as first-line treatment for metastatic non-ccRCC [2], others have found that Sunitinib may be better than Everolimus [1].

\section{CONCLUSION}

Everolimus adjuvant to radical nephrectomy allowed us to achieve a less-than-a-year survival in our patient. No new metastases appeared but no significant regression was achieved in the pre-existing metastases.

\section{Conflict of Interest: Nil.}

Financial Support: Nil.

\section{REFERENCES}

1. Fernandez-Pello S, Hofmann F, Tahbaz R, Marconi L, Lam TB, Albiges L, Bensalah K, Canfield SE, Dabestani S, Giles RH, Hora M. A systematic review and meta-analysis comparing the effectiveness and adverse effects of different systemic treatments for non-clear cell renal cell carcinoma. European urology. 2017 Mar 1;71(3):426-36.

2. Bedke J, Gauler T, Grünwald V, Hegele A, Herrmann E, Hinz S, Janssen J, Schmitz S, Schostak M, Tesch H, Zastrow S. Systemic therapy in metastatic renal cell carcinoma. World journal of urology. 2017 Feb 1;35(2):179-88. 